\title{
DETERMINISMO E CONHECIMENTO DE DEUS COMO LIBERDADE NA FILOSOFIA DE ESPINOSA
}

\section{DETERMINISM AND KNOWLEDGE OF GOD AS FREEDOM IN THE PHILOSOPHY OF SPINOZA}

\author{
Carlos Bezerra de Lima Júnior ${ }^{1}$ \\ Renan Pires Maia ${ }^{2}$
}

Recebido em: 07/2018

Aprovado em: 10/2018

\begin{abstract}
Resumo: O presente estudo procura mostrar a relação do conhecimento com as afecções na filosofia de Espinosa, e como isso se dá dentro de uma realidade determinista. O artigo demonstra como o conhecimento adequado da natureza, que é a intuição, conduz o homem à liberdade, que é a autodeterminação. Trata-se de uma pesquisa bibliográfica concernente às obras de Espinosa e comentadores como literatura de apoio.

Palavras-chave: Espinosa. Determinismo. Intuição. Afecções. Liberdade.
\end{abstract}

\begin{abstract}
This study aims to show the relation of knowledge to the affections in the philosophy of Spinoza, and how it takes place within a deterministic reality. The article demonstrates how the adequate knowledge of nature, which is the intuition, leads man to freedom, which is the selfdetermination. This is a bibliographical research concerning the works of Spinoza and commentators as supporting literature.
\end{abstract}

Keywords: Spinoza. Determinism. Intuition. Affections. Freedom.

\section{Introdução}

A filosofia de Espinosa é essencialmente prática - ela tem como fim acertar a conduta humana, acertar no sentido de corrigir e direcionar. Para o autor, um intelecto que pensa corretamente alcança a felicidade. Contudo, para se chegar a essa felicidade, é necessário pensar em como o homem deve agir no mundo. $\mathrm{O}$ mundo não poderia aparecer sendo simplesmente admitido - é por isso que a Ethica começa a partir de noções universais e abstratas sobre a

\footnotetext{
${ }^{1}$ Graduado em Filosofia pela UFPB. Mestre em Filosofia pela UFPB. Email: carlosbljr@gmail.com

${ }^{2}$ Graduado em Psicologia pela UFPB. Mestre em Filosofia pela UFPB. Doutorando em Filosofia pela UFPB. Docente da Faculdade Santíssima Trindade, Nazaré da Mata- - PE. Email: renanpmaia@gmail.com
} 
Natureza, identificada com Deus ${ }^{3}$. E uma das coisas que são logo abordadas insistentemente pelo autor na parte I, que Espinosa nomeará "De Deo", é aquilo que chamamos de determinismo.

Espinosa insere seu leitor na ideia de que não há espaço para o "possível”, ou o "provável". Tais termos são pensados pelo homem de modo imaginativo, que é uma espécie de defecção de sua inteligência. Uma vez que o homem compreende adequadamente a realidade, vislumbrará o mundo como é: sem um “possível”, mas com um “inevitável”. Porém, se todas as coisas são do jeito que são necessariamente, onde o homem encontra, na esfera da amplitude de suas forças, a possibilidade de adquirir liberdade ou a potência de agir autonomamente?

A ética de Espinosa é um sistema interconectado com sua epistemologia, e dependente dela. Está sob a égide do conhecimento a possibilidade de liberdade, e também da servidão, pois é o conhecimento que determina a dinâmica interativa do homem com o mundo: tal dinâmica faz do homem padecente por impotência, ou ativo por autodeterminação. A estrutura ética do autor é logicamente concatenada nesse sentido. Faz parte dessa ascensão do homem à condição de livre o entendimento da inevitabilidade do fato que constitui a vida em cada momento, a visualização do que lhe está à mão dentro de uma realidade pétrea, mas regozijável. Trata-se de um conhecer adequado ao que é.

Espinosa procurará explicar o modus operandi da mente humana, e nesse intercurso mapeia os modos em que o homem adquire conhecimento. Dependendo de como o homem conhece, ele é afetado de maneira a padecer. A paixão é, para Espinosa, produto de um conhecimento inadequado. É curioso que para o autor, menos importa que o mundo seja dado ao homem: mas o homem é dado ao mundo, e o perigo se encontra na ignorância, pois esta está atrelada à servidão humana.

A intuição, que Espinosa chama na Ethica de terceiro gênero de conhecimento, é um tipo adequado de conhecimento - que capta a essência das coisas, e de Deus. Através dessa ciência o homem sobrepuja a pressão ambiental; mas nem por isso deixa de estar sendo determinado, só que com uma diferença, e este é o presente que lhe é dado pela intuição: a determinação será autodeterminação. Portanto, o presente estudo busca explicar como se dá a liberdade humana em um corpus teórico determinista, ou necessitarista.

\section{Determinismo e afecções}

\footnotetext{
${ }^{3}$ Daí a expressão Deus sive natura. Embora, para o autor, natureza não seja o mesmo que matéria, que seria correspondente à extensão, um dos infinitos atributos de Deus.
} 
Nos é conveniente considerar que em muitas passagens Espinosa leva seu leitor a entender que há uma espécie de determinismo no seu pensamento. Uma das passagens em que isso fica positivado com fim de estabelecer essa própria ideia se dá na seguinte proposição: "Na natureza das coisas nada é dado de contingente, mas tudo é determinado pela necessidade da natureza divina a existir e operar de maneira certa" (prop. XXIX, pt. I). ${ }^{4}$ Nada é ou está por acaso. As coisas ou fatos não se dão contingentemente, mas necessariamente.

Dizemos que não há nada contingente na filosofia de Espinosa na medida em que todas as coisas são determinadas - são necessárias. Na verdade, é natural contrapor aquilo que é necessário com aquilo que é contingente e, ao dizer que não há nada contingente, Espinosa poderia parecer excluir a possibilidade de pensarmos na contingência em sua filosofia. Entretanto, ele incorpora também na sua Ethica a noção de contingente: "Chamo contingentes as coisas singulares, enquanto, ao prestarmos atenção à só essência delas, nada encontramos que ponha necessariamente sua existência ou que necessariamente a exclua" (def. III, pt. IV). Isso não contradiz o que o autor expõe na parte I, conforme citamos acima, porque as coisas seriam contingentes conquanto pensamos em suas essências isoladamente: sua existência factual ou não é sempre necessária, e não pode não a ser.

Bennett distingue duas formas de necessidade no interior da filosofia de Espinosa: uma que se dá em relação às próprias leis da física, uma vez que a extensão, enquanto atributo de Deus, possui também um caráter absoluto, “o que satisfaz as demandas explanatórias do racionalismo na medida em que as leis físicas são consideradas" (BENNETT, 2006, p. 74), e um que se aplica às questões factuais, tais como o fato "de uma telha ter recém caído do meu telhado (...), tal foi causado por um vento, que foi causado por outro movimento do ar, o qual foi causado por... e assim por diante; o determinismo estrito reina, e a cadeia causal deve voltar para sempre" (BENNETT, idem).

Para Espinosa, até mesmo as coisas livres são determinadas: "É dita livre aquela coisa que existe a partir da só necessidade de sua natureza e determina-se por si só a agir" (def. VII, pt. I). A coisa livre é autodeterminada a agir, mas ainda determinada. Deus, que é sumamente livre, existe necessariamente: "Deus, ou seja, a substância que consiste em infinitos atributos,

\footnotetext{
${ }^{4}$ As referências de Espinosa remetem sempre à edição crítica de C. Gebhardt. Contudo, na citação em português contemplamos a literatura nacional utilizando edições brasileiras e, no caso do Tratado Breve, a edição espanhola. Organizamos as citações da Ethica da forma seguinte ao exemplo: "prop. XXIX, pt. I" se refere à proposição XXIX da parte I da Ethica. Ainda outro exemplo: "def. III, pt. IV" se refere à definição III da parte IV da mesma obra.
} 
dos quais cada um exprime uma essência eterna e infinita, existe necessariamente" (prop. XI, pt. I); ele age pela necessidade de sua natureza (prop. XVII, pt. I). De outra forma, Espinosa diz que “As coisas não puderam ser produzidas por Deus de nenhuma outra maneira e em nenhuma outra ordem do que aquelas em que foram produzidas" (prop. XXXIII, pt. I). Ademais, "Tudo que é, é em Deus, e nada sem Deus pode ser nem ser concebido" (prop. XV, pt. I). Espinosa é um crítico de sua tradição na medida em que se coloca adverso à ideia de um Deus transcendente, separado do mundo, como diz na sua prop. XVIII da pt. I: "Deus é causa imanente de todas as coisas", sobretudo porque não mede esforço para demonstrar que o homem não deve ser tomado como especial, sobre a natureza, mas dentro e sob ela, ao jugo das leis naturais.

Há momentos na Ethica em que o leitor mais conhecedor da tradição percebe certas linhas dedicadas à referência tradicional, quase sempre em crítica. Espinosa se contrapõe em vários momentos a Descartes, quando fala sobre a relação entre alma e corpo, ou aos escolásticos, no que se refere à ideia de Deus antropomórfico. Enfim, ao tratar da questão das afecções, Espinosa logo de início, no prefácio da pt. III diz:

Quase todos que escreveram sobre os Afetos e a maneira de viver dos homens parecem tratar não de coisas naturais, que seguem leis comuns da natureza, mas de coisas que estão fora da natureza. Parecem, antes, conceber o homem na natureza qual um império num império. Pois creem que o homem mais perturba do que segue a ordem da natureza, que possui potência absoluta sobre suas ações, e que não é determinado por nenhum outro que ele próprio. (SPINOZA, 2015, p. 233)

No que se refere às afecções, Espinosa se mantém firme ao dizer que os afetos do homem também são coisas da natureza, e não são especiais, mas participam da dinâmica da vida assim como os corpos que com o homem interagem e o afetam:

os Afetos de ódio, ira, inveja, etc., considerados em si mesmos, seguem da mesma necessidade e virtude da natureza que as demais coisas singulares, e admitem, portanto, causas certas pelas quais são entendidos, e possuem propriedades certas, tão dignas de nosso conhecimento quanto as propriedades de qualquer outra coisa cuja só contemplação nos deleita. (prefácio, pt. III).

Se o homem e seus afetos também são determinados, se sua relação com os demais elementos que compõem seu mundo é uma sequência de efeitos necessários e fatos certos, isso quer dizer que as coisas ocorrem porque precisam ocorrer. Entre duas escolhas, a partir do ponto de vista da eternidade, o homem é determinado a escolher uma, muito embora que do seu ponto 
de vista, ele imagine que ambas sejam possíveis (trata-se de um olhar inadequado sobre a realidade, como será mostrado adiante).

Rizk, em comentário sobre a dinâmica dos afetos, diz que

Um indivíduo tem, de fato, necessidade de outras coisas para existir, e muitas coisas têm uma potência que excede à sua; a existência dos indivíduos singulares implica uma interação modal, quer dizer, uma forma de co-pertença dos indivíduos uns aos outros, a vis existendi (força de existir) própria a cada essência singular está ligada às determinações externas que permitem atualizar-se. É preciso, por conseguinte, conceber uma reciprocidade entre, de um lado, a potência imanente a cada essência e, de outro lado, a composição em exterioridade dos modos: a atualização de cada essência constitui a condição da atualização das outras essências, ao mesmo tempo que ela se encontra condicionada por elas (RIZK, 2006, p. 115).

O que caracteriza os afetos, portanto, é não apenas a necessidade que cada coisa tem de outras - o que poderíamos chamar de inclinação interna, para distinguir da necessidade causal - mas também a necessidade que as outras coisas também têm, formando toda uma teia de relações e, sobretudo, de tensões. As diferentes coisas que compõem (relativamente) a realidade enquanto modificações do próprio Deus imanente estão, deste modo, atadas umas às outras, e vivem não de modo isolado, como mônadas fechadas em si e que não se afetam reciprocamente senão fenomenicamente ${ }^{5}$, mas se encontram numa rede na qual cada coisa afeta a outra e cada uma se vê arrastada num fluxo contínuo e irresistível de necessidade causal, da qual ela própria faz parte, e que não apenas a afeta mas, em última instância, a define e determina.

Percebemos de modo ainda mais nítido a natureza desse fluxo quando consideramos conceitos como o de Conatus, que é o esforço de cada coisa por perseverar em seu ser (prop. VI, pt. III) - e que nada mais é do que a essência atual de cada coisa (prop. VII, pt. III) - e a dinâmica que os diferentes conati mantêm entre si. O conatus, poderíamos dizer, nada mais é do que a resistência que cada coisa oferece frente à torrente causal que a tudo tende a arrastar. Este é possivelmente um dos motivos para Spinoza introduzir, na pt. III, o conceito de conatus após tratar, nas prop. IV e V sobre contrariedade e luta entre os diferentes modos.

Considerando que, para perseverar na existência, muitas coisas precisam afetar ou mesmo aniquilar outras, podemos constatar que a realidade na qual cada coisa particular está imersa é uma realidade de constante luta e contrariedade, a qual se manifesta no interior do corpo através das afecções e, no interior da mente, através das ideias. Os afetos nada mais são,

\footnotetext{
${ }^{5}$ Vide a Monadologia de Leibniz.
} 
por assim dizer, do que manifestações da causalidade entre as coisas, e como tal, seguem uma necessidade. São manifestações do conatus do homem em sua interação com todos os demais conati que, não só igualmente se esforçam para perseverar na existência, mas também, nesse perseverar, se esforçam para sobrepujar o conatus do homem.

Além disso, poderíamos dizer que os próprios afetos estão, entre si, em luta e em relação de contrariedade no interior do homem. É o que Espinosa diz quando afirma, na def. V da pt. IV, que há afetos contrários que arrastam o homem para direções diferentes e que, na prop. VII da pt. IV, um afeto não pode ser refreado nem anulado senão por um afeto contrário e mais forte. Assim sendo, os afetos estão completamente no reino da necessidade da natureza, diferentemente do que postula toda uma tradição que vê na vontade do homem algo incondicionado e livre, exterior ao reino natural.

Uma visão necessitarista e determinista permeia o pensamento de Espinosa, de modo que nada existe que não siga uma ordem certa e necessária, o que se aplica tanto às coisas exteriores ao homem quanto às interiores (como seus afetos). Desse modo, poderíamos dizer que Espinosa, antes de defender a existência de um libero arbitrio, defende a existência de um servo arbítrio - para usar uma linguagem teológica -, sendo a vontade humana arrastada por uma necessidade inevitável, que inclui seus afetos e paixões, que mediam sua relação com as demais coisas. De fato, no capítulo VI do Breve Tratado (SPINOZA, 1990, p. 85-88), Espinosa chega a falar da necessidade com que todas as coisas procedem de Deus como sendo predestinação, predestinação esta que se aplicaria a todas as coisas em todos os âmbitos da existência. $^{6}$

Mas, como na teologia, cujo determinismo a que parece conduzir noções como predestinação, providência, presciência etc. levanta imediatamente a questão de que espaço há para o livre-arbítrio humano, o necessitarismo espinosano nos impulsiona a questionar sobre o conceito de liberdade, o qual, independente de determinismo, não deixa de ser abordado, principalmente na parte V da Ética, cujo título é A potência do intelecto e a liberdade humana. A tentativa de conciliação entre a liberdade do homem e a soberania de Deus e de seus eternos decretos misturaram historicamente teologia e metafísica naquilo que ficou conhecido como o problema dos futuros contingentes, abordado já por Santo Agostinho e também, nos tempos de Espinosa, por Leibniz. Diante da conclusão de que não há contingências na filosofia de

\footnotetext{
${ }^{6}$ Domínguez, em comentário ao capítulo, afirma que há estudos (realizados por M. Francès) sobre o impacto da obra do reformador João Calvino - que se distingue por sua ênfase na noção de predestinação - no pensamento de Espinosa, considerando que o calvinismo era a religião de Estado na Holanda do séc. XVII (DOMÍNGUEZ, 1990, p. 227-228).
} 
Espinosa, podemos pensar que não há espaço algum para a liberdade. Se entendermos a liberdade como o agir independentemente de qualquer necessidade ou determinado por causas finais (que no plano do agir são as intenções), certamente ela inexiste. ${ }^{7}$

O ponto central no tocante à liberdade em Espinosa está precisamente na definição. Já na primeira parte da Ética, Espinosa define como livre "a coisa que existe a partir da só necessidade de sua natureza e determina-se por si só a agir” (def. VII, pt. I). Parece estranho que Espinosa coloque numa mesma e única definição termos como "livre" e "necessidade", em geral entendidos como antitéticos. A liberdade, segundo a definição, é necessidade, embora necessidade interna, não coagida por outros fatores, como nos fica claro na continuação da definição: "Porém, necessária, ou antes coagida, aquela que é determinada por outro a existir e a operar de maneira certa e determinada" (idem). Chauí, a respeito da noção de liberdade de Espinosa, diz:

Espinosa retoma a noção clássica da liberdade como espontaneidade de uma natureza na ausência de constrangimento externo, acrescentando-lhe, porém, a ideia paradoxal de necessidade livre, isto é, de uma necessidade espontânea que brota da essência do próprio ser, contrapondo-a à necessidade de uma causa externa que força alguma coisa a uma existência ou ação que, por si mesma, não possuiria nem realizaria. A diferença, portanto, não se estabelece entre liberdade e necessidade, e sim entre liberdade e constrangimento, e o que diferencia o constrangimento da liberdade não é a ausência (nela) ou a presença (nele) da necessidade, mas a interioridade ou exterioridade da causa que a incita a existir e agir (CHAUI, 1999, p. 78).

Após desenvolver na parte I sua visão imanentista e também determinista e, na parte II, sua epistemologia, Espinosa introduz, na parte III, o conceito de ação, o qual será contraposto ao conceito de padecimento. $\mathrm{O}$ agir para Espinosa estará estreitamente vinculado com a noção de liberdade, e o padecimento, com a noção de servidão. De acordo com o autor, na def. 2 da pt. III, "agimos quando ocorre em nós ou fora de nós algo de que somos causa adequada, isto é, quando de nossa natureza segue em nós ou fora de nós algo que pode ser entendido clara e distintamente só por ela mesma", e que "padecemos quando em nós ocorre algo, ou de nossa natureza segue algo, de que não somos causa senão parcial”, entendendo causa adequada como "aquela cujo efeito pode ser percebido clara e distintamente por ela mesma" (def. I, pt. III) e, inadequada ou parcial, “aquela cujo efeito não pode só por ela ser entendido” (idem).

\footnotetext{
${ }^{7}$ Sobre a inexistência das causas finais, Espinosa afirma, no apêndice da pt. I: "não é preciso muito trabalho para que agora eu mostre que a natureza não tem para si nenhum fim prefixado e que todas as causas finais não são senão humanas ficções" (SPINOZA, 2015, p. 115).
} 
Nesse sentido, a liberdade, como se depreende da definição VII da parte I e das definições. II e III da parte III, é o mesmo que agir, isto é, é ser causa adequada. Mas isso não exclui a necessidade, mas é um agir segundo a necessidade interna da própria natureza observe-se que na própria definição de liberdade já figura o conceito de ação. Aquilo que é coagido, por outro lado, é aquilo que é determinado por outra coisa a existir e a operar, ou, em outras palavras, aquilo que não é causa adequada de sua própria existência ou operação. Há um íntimo entrelaçamento entre todas estas definições.

O poder [de agir] ou esforço que constitui a essência de qualquer indivíduo, enquanto sempre "ligado" e constante, não permanece inalterado durante toda a vida de uma pessoa, mas é constantemente sujeito a alterações. Em particular, o poder pode desfrutar de um aumento ou reforço ou pode sofrer uma redução ou diminuição. (Um extermínio completo ou mesmo uma transformação radical dessa potência é, é claro, a morte.) Qualquer tal mudança no poder de um indivíduo de agir, para melhor ou para pior, é o que Spinoza chama de "afecção". (NADLER, 2006, p. 200)

Na definição III da parte III Espinosa define afeto como "as afecções do Corpo pelas quais a potência de agir do próprio Corpo é aumentada ou diminuída (...) e simultaneamente as ideias destas afecções", especificando que quando somos causa adequada de uma afecção, o afeto é uma ação, e quando não o somos, o afeto é uma paixão (SPINOZA, 2015, p. 237). Disso se segue que nem todo afeto faz o homem padecer ou é uma paixão, mas há também aqueles que estimulam a potência de ação do homem. Atendo-nos um pouco mais a esta última definição, perceberemos que Espinosa coloca como fatores que aumentam ou diminuem a potência de ação não apenas as afecções do corpo, mas suas ideias correspondentes, o que nos abre um caminho para o conhecimento e para consequente relação entre a ação ou paixão e as potências cognoscitivas da mente.

\begin{abstract}
A mente age seguindo sua própria natureza e suas próprias leis quando sua condição é resultado de seus próprios recursos cognitivos. E um estado da mente resulta dos próprios recursos da mente quando tem idéias adequadas. Por outro lado, quando um estado da mente é resultado não de idéias adequadas na mente, mas da uma ideia inadequada do corpo humano, juntamente com a ideia inadequada de alguma coisa externa que está presentemente causando alguns efeitos no corpo humano, aquele estado mental não resulta dos próprios recursos da mente e é consequentemente uma paixão. (NADLER, 2006, p. 193-194)
\end{abstract}

Esta abordagem dos afetos sob um duplo aspecto - o de nível corporal e o de nível 
mental - é um desenrolar lógico da relação de identidade existente entre o corpo e sua ideia, que é a mente, relação esta explorada ao longo da parte II (a partir da prop. XI). Corpo e mente nada mais são do que uma e mesma coisa, compreendida sob dois aspectos ou dois atributos diferentes de Deus: o atributo da extensão e o do pensamento. O ser humano é o ser humano em sua totalidade, e "O que quer que aconteça no objeto da ideia que constitui a Mente humana deve ser percebido pela Mente humana" (prop. XII, pt. II), isto é, todas as afecções do corpo estão referidas à mente, e a mente nada conhece, nem de si mesma (prop. XIX e XXIII, pt. II) nem de qualquer outra coisa, senão na medida em que o corpo é afetado. A relação entre o corpo e a mente é, novamente, uma relação de identidade, e afetos, paixões, ações etc. e conhecimento possuem uma relação indissociável.

\section{O conhecimento de Deus como liberdade}

O projeto de Espinosa mostra como é possível uma ética num mundo onde tudo é determinado. Segundo o autor, a liberdade no homem, bem como sua beatitude e felicidade estão intimamente ligados ao conhecimento, no Tractatus de intellectus emendatione, Espinosa diz que

faz parte de minha felicidade o esforçar-me para que muitos outros pensem como eu e que seu intelecto e seu desejo coincidam com o meu intelecto e o meu desejo; e, para que isso aconteça, é necessário compreender a Natureza [Deus] tanto for preciso para adquirir aquela natureza (SPINOZA, 2004, p. 11). ${ }^{8}$

Essa compreensão que Espinosa se refere coincide com uma união, porque para o autor, como diz Lívio Teixeira (2004, p. XII), “Amamos aquilo que conhecemos”. Porém, para alcançar esse bem, que é identificado na passagem citada como felicidade, o autor reconhece que é necessário "Conhecer exatamente nossa natureza, que desejamos levar à perfeição e, igualmente, conhecer a natureza das coisas" (SPINOZA, 2004, p. 17). No caso, a condução em direção ao bem se dá pela via do conhecimento. Para isso, Espinosa estabelece, na Ética (escólio II, prop. XL, pt. II), três níveis de conhecimento. O primeiro abrange dois subníveis:

\footnotetext{
${ }^{8}$ Longe de pensar, com estes termos, de modo anti-democrático, como alguém que quer apenas adequar os demais a si, Espinosa fala como alguém que decobriu em Deus e no correto conhecimento de Deus o - provavelmente único fundamento para uma ética, algo que deve ser compartilhado com os demais a fim de que todos alcancem a virtude e a felicidade, que, no pensamento espinosano, são inteiramente conciliáveis.
} 
$\mathrm{I}^{\circ}$ a partir de [coisas] singulares, que nos são representados pelos sentidos de maneira mutilada, confusa e sem ordem para o intelecto. (...) II $^{\circ}$ A partir de signos; por exemplo, de que, ouvidas ou lidas certas palavras, nos recordamos das coisas e delas formamos ideias semelhantes àquelas pelas quais imaginamos as coisas (SPINOZA, 2015, p. 201).

A este primeiro modo de conhecimento Espinosa chama conhecimento de primeiro gênero, opinião ou imaginação. Há ainda o segundo gênero, que se dá a partir de "noções comuns e ideias adequadas das propriedades das coisas" (SPINOZA, idem), que é o conhecimento racional, e um último, que "procede da ideia adequada da essência formal de alguns atributos de Deus para o conhecimento adequado da essência das coisas" (SPINOZA, idem), conhecimento este que se dá de modo imediato - como Espinosa o expressa no exemplo da quarta proporcional, e o qual é posteriormente chamado de conhecimento intuitivo. Como diz Nadler (2006, p. 181), "Intuição representa um tipo de compressão epistêmica de informação. Ela envolve uma apreensão direta da relação causal e lógica entre os termos, de tal modo que a informação é unida em algo agarrado em um simples ato da mente".

Convém observar que o conhecimento imaginativo é a fonte de todo erro, enquanto que a razão e a intuição são necessariamente fontes de todo conhecimento verdadeiro (prop. XLI, pt II). Espinosa define o conhecimento adequado como uma ação da mente, isto é, quando a mente é causa adequada de uma ideia (ou quando a ideia é explicada apenas pela natureza da mente), enquanto o conhecimento confuso ou imaginativo é fruto de um padecimento da mente, isto é, de quando a mente não é causa adequada de suas ideias. Poderíamos dizer que a mente, quando conhece adequadamente, é livre, e quando padece e é coagida, erra. Mas é preciso lembrar, uma vez mais, da totalidade que é o homem, de modo que, se a mente padece, também padece o corpo, e vice-versa, de modo que conhecimento e prática são indissociáveis, formando uma ética.

Mas a pergunta que fica é: diante do fato de que Espinosa está tentando construir uma ética, e considerando o fato de que tudo o que acontece na ordem das coisas (seja a partir do prisma da extensão ou do pensamento, pois nada é contingente) segue uma ordem necessária, o que pode o homem fazer para alcançar a virtude? O determinismo espinosano parece, à primeira vista, conduzir à conclusão de que ao homem tanto faz a virtude ou a não-virtude (se é que se pode fazer tal distinção num sistema absolutamente determinista), uma vez que nada pode fazer por si.

É verdade que, no pensamento espinosano, o homem não pode mudar o rumo das coisas, 
quer no nível das coisas corporais ou no nível da mente, no tocante ao querer (apêndice, pt. I; e prop. XLVIII, pt. II), e que tampouco o corpo pode determinar a mente a pensar ou a mente determinar o corpo ao movimento ou ao repouso (prop. II, pt. III), visto que são uma mesma coisa, e não duas coisas diferentes que se afetam. Deleuze afirma que

uma das teses mais célebres de Espinosa é conhecida pelo nome de paralelismo: ela não consiste apenas em negar qualquer ligação de causalidade real entre o espírito e o corpo, mas recusa toda a eminência de um sobre outro. Se Espinosa recusa qualquer superioridade da alma sobre o corpo, não é para instaurar uma superioridade do corpo sobre a alma, a qual não seria mais inteligível. A significação prática do paralelismo aparece na inversão do princípio tradicional em que se fundava a Moral como empreendimento de dominação das paixões pela consciência: quando o corpo agia, a alma padecia, dizia-se, e a alma não atuava sem que o corpo padecesse por sua vez (regra da relação inversa, cf. Descartes, Tratado das Paixões, artigos 1 e 2) (DELEUZE, 2002, p. 24).

A noção de paralelismo psicofísico à qual Deleuze se refere não deixa de ter as devidas limitações e problemas, como nos aponta Chauí na Nervura do real (CHAUI, op. cit., p. 736740). Independentemente disso, é indiscutível que a relação entre o espírito e o corpo não é causal, mas de identidade 9 . Todavia, podemos dizer que há no pensamento de Espinosa um espaço para que o conhecimento - que é em si mesmo uma ação da mente - opere como um fator que faz com que o homem se veja livre do padecimento e das paixões (embora não dos afetos em geral), não no sentido de que o conhecimento pode determinar o homem a se movimentar em uma direção ou outra de modo contingente, mas no sentido de que o próprio (re)conhecimento da necessidade inevitável e eterna do curso das coisas faz com que o homem sofra menos e mantenha-se resignado e, inclusive, alegre diante dos diferentes acontecimentos que a necessidade causal do mundo traz para si.

Conhecer, para Espinosa, é conhecer através das causas (axioma IV, pt. I), o que é condizente com seu método sintético e geométrico, o qual parte de causas adequadas para daí deduzir os efeitos. Tal modo de proceder se aplica de igual modo aos acontecimentos do mundo e da vida de um ser humano. Não há causas finais, causas livres, acasos ou contingências em Espinosa, mas apenas causas eficientes que determinam seus efeitos, de modo que o conhecimento de tudo o que acontece depende do conhecimento da necessidade da conexão entre o efeito e sua causa eficiente. Não cabe, portanto, diante do conhecimento adequado de

\footnotetext{
${ }^{9}$ Prop. XXII, pt. II: “a ideia do corpo e o corpo, isto é, a mente e o corpo, são um único e mesmo indivíduo, concebido ora sob o atributo do pensamento, ora sob o da extensão" (SPINOZA, op. cit., p. 115).
} 
um acontecimento que consideramos um revés, o pensamento de que aquilo poderia ser evitado ou poderia ter se dado de uma outra maneira. Por essa perspectiva, o reconhecimento e a compreensão da necessidade é a própria liberdade, um refreador das paixões que fazem o homem sofrer, se ressentir ou se revoltar com o curso das coisas. Tal é, por exemplo, demonstrado na prop. VI da parte V, onde Espinosa afirma que "Enquanto a Mente entende todas as coisas como necessárias, nesta medida tem maior potência sobre os afetos, ou deles padece menos". A compreensão da necessidade das coisas e também dos afetos é um conhecimento claro e distinto que formamos. No caso dos afetos que são paixões, tal conhecimento faz com que o afeto deixe de ser uma paixão, como diz o autor na prop. III da parte $\mathrm{V}$.

É preciso pontuar, ainda, que a liberdade em relação às paixões que o conhecimento adequado do curso das coisas e das próprias coisas proporciona não para apenas com o reconhecimento da necessidade, mas vai além, vinculando-se de modo íntimo ao conhecimento de Deus. Na parte V Espinosa explora a relação de todas estas coisas com o conhecimento de Deus que nasce por meio do terceiro gênero, que se dá de modo imediato ou intuitivo - isto é, não se dá a partir de mediações, e é suprarracional, posto que é distinto do conhecimento do segundo gênero - e ao qual Espinosa vincula um modo de conhecimento sub specie aeternitatis, como nos fica claro na demonstração da prop. XXXI, da parte V. O conhecimento das coisas sob a perspectiva da eternidade é o conhecimento das coisas tal como Deus as conhece, isto é, como "concebida necessariamente pela própria essência de Deus" (demonstração da prop. XXII, pt. V).

O conhecimento de Deus e o conhecimento da necessidade do curso das coisas são duas coisas intimamente ligadas. Fugindo das discussões e controvérsias a respeito de que Deus é o Deus de Espinosa - para todos os efeitos, Espinosa fala de um Deus -, podemos dizer que ele, inclusive, deduz a necessidade do curso das coisas de sua suprema causa, Deus, ou, o que é o mesmo, a substância única. Chauí, a esse respeito, afirma que

Nada há de contingente na Natureza, explica Espinosa no Breve tratado e nos Pensamentos metafísicos, e o demonstra na Ética. Assim como a essência e a potência necessárias da substância a fazem causa de si livre porque necessária, isto é, espontaneidade infinita que é sua própria natureza, assim também a necessidade se transmite a todas as suas modificações. Os modos finitos são duplamente determinados: sua essência é determinada pela essência e potência dos atributos substanciais, e sua existência é determinada por séries causais que regem a Natureza Naturada (CHAUI, op. cit., p. 77). 
Isso nos fica claro em passagens como a prop. XVII da parte I, em que Espinosa afirma que Deus age exclusivamente pelas leis de sua natureza (o que é liberdade e ao mesmo tempo necessidade) e que não apenas não poderia fazer as coisas de outro modo, mas que faz necessariamente tudo aquilo que está contido em seu pensamento, sendo tal o modo mais adequado de entendermos a onipotência divina. Também nos fica claro na prop. XXXIII, parte I, em que Espinosa diz que as coisas não poderiam ter sido produzidas por Deus de nenhuma outra maneira nem em qualquer outra ordem que não naquelas em que foram produzidas, posto que, se o curso das coisas fosse diferente, a natureza de Deus seria outra, uma vez que tudo se segue necessariamente da natureza de Deus. Difere-se, portanto, de Leibniz com seus infinitos mundos possíveis, dos quais apenas um - o melhor - é real. Para Espinosa só um mundo é possível: o que existe, e postular que Deus poderia fazer algo diferente do que faz, como Leibniz, é, não apenas conceber Deus e as coisas de forma confusa e imaginativamente, mas também padecer e sofrer.

Assim, a mente pode referir tudo a Deus, que é causa sui e causa adequada de todas as coisas que dele se seguem. Do mesmo modo pode referir a Deus todas as afecções do corpo (prop. XIV, pt. V), formando delas um conhecimento claro e distinto (sobretudo considerando que o conhecimento claro e distinto envolve o conhecimento das causas, e que a causa adequada de todas as coisas é Deus) ${ }^{10}$. O conhecimento adequado dos afetos não apenas faz com que eles deixem de ser paixões, como dito acima, mas também proporciona o conhecimento de - e o amor a - Deus (prop. XV, pt. V), ou vice-versa. Eis ao que parece conduzir toda a ética espinosana. E este amor a Deus e compreensão dos próprios afetos é o que Espinosa chama de beatitude, a qual não nasce do fato de refrearmos os apetites lúbricos, mas refreamos os apetites lúbricos porque a desfrutamos (prop. XLII, pt. V), o que reforça seu caráter imediato, visto nascer do terceiro gênero de conhecimento, que é o conhecimento intuitivo de Deus (idem).

\section{Conclusão}

Como podemos perceber do que foi dito, o determinismo é patente na filosofia de Espinosa. Todavia, isso não impede a possibilidade de uma ética no interior de seu pensamento, isto é, a possibilidade de uma ação e libertação do homem em algum sentido e do alcance do bem - ou do que é útil ao homem (def. I, pt. IV). Pelo contrário: o conhecimento para Espinosa

\footnotetext{
${ }^{10}$ Note-se que aquilo que Espinosa chama, no Tratado Breve, de predestinação e providência, se impõe sobre todas as coisas existentes, quer exteriores ou interiores ao homem.
} 
assume um caráter essencialmente prático. Não à toa, Ética é o nome de sua magnum opus.

Também podemos constatar que Espinosa, na mesma medida em que se contrapõe a toda uma tradição de pensadores, que inclui Santo Agostinho e, na sua época, Leibniz, encarna diferentes concepções e influências, levando-as às últimas consequências ao incorporá-las em sua ética. Podemos observar isso com relação à supracitada noção de predestinação e de necessidade à qual a vontade está atada; em relação à sua concepção de Deus como imanente ao Universo, compreendendo este como um todo infinito - convém lembrar que a extensão, como atributo de Deus, é infinita - e que em algum sentido "esgota" tudo o que está contido no pensamento divino, o que nos remete às concepções de Giordano Bruno em Sobre o Infinito, o Universo e os mundos. Tais noções estariam, como demonstrado, todas associadas à visão espinosana de uma natureza regida pelo determinismo e sem espaço para contingências ou outros mundos possíveis.

Do mesmo modo, podemos afirmar, indissociavelmente ligada a tudo isso está sua concepção de liberdade, que não nega a necessidade, mas antes resgata traços do pensamento estoico, onde o homem, longe de lutar contra os fatos da vida, os aceita resignadamente, sendo o ápice da liberdade uma $\dot{\alpha} \tau \alpha \rho \alpha \xi i ́ \alpha$ ou uma $\alpha \dot{\pi}$ oví $\alpha^{11}$ diante dos acontecimentos, das coisas e dos próprios afetos, quer julguemos estas coisas boas ou más.

Por fim, podemos constatar como todas estas coisas estão atadas à noção de Deus - quer o determinismo ou a possibilidade de libertação. O determinismo é um desenvolvimento lógico da noção de Deus defendida pelo autor, assim como a liberdade é o correto conhecimento de Deus, que tudo inclui. Podemos acrescentar ainda a isso o fato de que apenas Deus é absolutamente livre de toda coação - uma vez que não possui nada diante ou fora de si que o possa constranger - e que a suprema liberdade do homem é não apenas reconhecer nas coisas a necessidade eterna da natureza divina, mas também um identificar-se com Deus, na medida em que, no interior da filosofia espinosana, não há espaço para dualidades ou multiplicidade. Tal identificação é o resultado do terceiro gênero do conhecimento, como nos aponta Brunschvicg:

O conhecimento do terceiro gênero, conhecimento intuitivo que marca o grau mais elevado da ciência, não comporta divisão nem análise; não procede por momentos distintos que corresponderiam cada um a uma parte definida da realidade; ele é uma síntese que compreende todo ser em sua indecomponível

\footnotetext{
11 A esse respeito há, como cita Domínguez (op. cit. ,p. 227-228), também estudos que rastreiam impactos da filosofia antiga, em especial o estoicismo, na filosofia de Espinosa, como o de Wim Klever: Voorbeschicking, Nimega, Markant, 1988.
} 
unidade (...) $\mathrm{Na}$ intuição, o pensamento está intimamente unido ao ser, é o próprio ser; a alma não é sujeito, não tem objeto, pois sujeito e objeto formam um só: ela é exatamente o que ela conhece (BRUNSCHVICG, 2014, p. 241).

Isto é, Deus.

\section{Referências}

BENNETT, J. Spinoza's metaphysics. In: GARRETT, D. The Cambridge companion to Spinoza. Cambridge: Cambridge University Press, 2006.

BRUNSCHVICG, L. Spinoza: filosofia e teologia. In: Estudos sobre Spinoza. Organização César Benjamin; tradução: Eliana Aguiar, Estela dos Santos Abreu, Vera Ribeiro. $1^{\mathrm{a}}$ ed. Rio de Janeiro: Contraponto, 2014.

CHAUI, M. S. A nervura do real: imanência e liberdade e Espinosa. São Paulo: Companhia das Letras, 1999.

DELEUZE, G. Espinosa: filosofia prática. São Paulo: Escuta, 2002.

DOMÍNGUEZ, A. Notas. In: SPINOZA. Tratado Breve. Traducción, prólogo y notas de Antilano Domínguez. Madrid: Alianza Editorial, 1990.

NADLER, S. Spinoza's Ethics: an introduction. Cambridge: Cambridge University Press, 2006.

RIZK, H. Compreender Spinoza. Tradução de Jaime A. Clasen. Petrópolis, RJ: Vozes, 2006.

SPINOZA. Opera. In Auftrag der Heidelberger Akademie der wissenchaften, herausgegeben von Carl Gebhardt. Heidelberg: Carl Winters, 1925; 2. Auflage, 1972, 4bd.

Ética. São Paulo: Editora da Universidade de São Paulo, 2015.

Tratado Breve. Tradución, prólogo y notas de Antilano Domínguez. Madrid: Alianza Editorial, 1990.

Tratado da reforma da inteligência. São Paulo: Martins Fontes, 2004.

TEIXEIRA, L. Introdução. In: SPINOZA. Tratado da reforma da inteligência. São Paulo: Martins Fontes, 2004. 